\title{
$\begin{array}{ll}\text { Research Square } & \text { Preprints are preliminary reports that have not undergone peer review. }\end{array}$ or referenced by the media as validated information. \\ In vitro bioassay of antibacterial and antifungal activity studies of actinomycetes from soda lakes of Ethiopia
}

\author{
Kenesa Chali ( $\square$ kcowscd1315@gmail.com) \\ Department of Applied Biology, Adama Science and Technology University https://orcid.org/0000- \\ 0001-5656-249X

\section{Zerihun Belay} \\ Department of Applied Biology, Adama Science and Technology University \\ Ketema Bacha \\ Jimma University, Jimma, Ethiopia
}

\section{Research Article}

Keywords: Actinomycetes, Antibiotics, Microbial diversity, Soda lakes, Streptomyces

Posted Date: June 29th, 2021

DOI: https://doi.org/10.21203/rs.3.rs-668562/v1

License: (c) (i) This work is licensed under a Creative Commons Attribution 4.0 International License.

Read Full License 


\section{Abstract}

The ever-increasing spectrum of microbial disease and emergence of life-threatening antibiotic-resistant pathogens necessitates more intensive search for microbial antagonistic agents from diverse symbionts and habitats. Based on these hypotheses the current study was initiated to investigate in vitro antibacterial and antifungal activities of both crude and pure compounds isolated from potential actinomycete isolates recovered from soda lakes of Ethiopia. Two soda lakes, Arenguade/Hora Hadho/ and Chitu were included in this study. A total of fifteen 12 water samples were collected and actinomycete cultures were isolated by serial dilution plating technique on various media. Morphological and biochemical characterization of selected isolates was done as described in the International Streptomyces Project Guidelines. Minimum inhibitory concentrations of the crude extract was determined for fungus using the protocol described in National Committee for Clinical Laboratory Standards and for the bacteria disc diffusion assay method as described in the Clinical and Laboratory Standards Institution. Ethanol extracts obtained from Solid State Fermentation a total of 36 isolates of actinomycetes were subjected to primary screening and tested for activity against the bacterial and fungal reference strain. Accordingly, the extracts from 10 isolates that were most active in the primary screen were 6 (16.66\%) from Lake Chitu that were inhibited the growth of Gram-positive bacteria and fungal strain; 4 (11.11\%) from Lake Arenguade that were inhibited Gram-negative bacteria and fungal. From evaluated the antibacterial and antifungal potential of two soda lakes water-derived actinomycetes; the best ones in terms of activity spectra were actinomycetes species isolated from Lake Chitu. Antibacterial and antifungal metabolite production was detected from isolates of Lake Chitu with maximum zone of inhibition within 5-6 days of incubation against Candida albicans ATCC 62376, Aspergillus niger, C. neoformans, F. oxysporum f. sp. melonis (CECT 20474), and Shigella boydii (clinical). All test microorganisms, except Staphylococcus aureus ATCC25923, E. coli ATCC 25922, and S. aureus (clinical isolate) were sensitive to the culture filtrate starting from 8-12 days of incubation. In terms of the effectiveness of the antibacterial activity, the antibacterial metabolite produced from different carbon sources were more effective on S. aureus (clinical isolate), A. niger, C. neoformans, S. aureus ATCC25923, Fusarium oxysporum f. sp. melonis (CECT 20474), Shigella boydii (clinical isolate) respectively. However, the most resistant test isolates with least activity was detected against Candida albicans ATCC 62376 and E. coli ATCC 25922.

\section{Background Of The Study}

The emergence of multi-drug resistant pathogens necessitates continuous search for novel antimicrobial agents. There is the continuous need for novel antibiotics to overcome the serious problem of evolving pathogens, naturally resistant bacteria and fungi, and multidrug resistance among common bacterial pathogens. Also, searching for novel strains from pristine environments is an important approach for obtaining novel bioactive molecules. Ironically, despite the extensive research done on antibioticproducing Streptomycetes, interactions of actinomycetes with other bacteria, the ecological rationale and physiological property of the Streptomycetes the extent to which produce antibiotics is the most striking and poorly understood [1]. Among the microbes, the secondary metabolites recovered from the soda lakes 
and untouched forest soil actinomycetes were more added values [2-6]. New resistant strains emerge more quickly while the rate of discovery of new antibiotics is slowing down. Today, superbugs are estimated to cause 700,000 deaths every year and are expected to rise to 10 million deaths each year by 2050 [7]. This necessitates screening for new and novel drugs producing microorganisms, including actinomycetes [8\&9).

In this regard, Ethiopian soda lakes and untouched soil habitats from various climatic zones possessing remarkable biodiversity may harbor new actinomycete strains that have the potential for new antibiotic discovery. Previous studies by a few investigators confirmed the existence of potential antibioticproducing actinomycetes from different ecosystems of Ethiopia. Accordingly, alkaliphilic actinomycetes capable of producing antimicrobial metabolites active against bacteria and fungi were isolated from Ethiopian soda lakes [10-12], rhizosphere of different plants, farmlands and garden soils [13 \&14]. Most microorganisms are still untapped in terms of their capacity to produce secondary metabolites since only a small fraction can be cultured in the laboratory. Thus, improving cultivation techniques to extend the range of secondary metabolite producers accessible under laboratory conditions is an important first step in prospecting underexplored sources for the isolation of novel antibiotics. For industrial application, further, purification, structural elucidation, characterization, and optimization of the culture condition are required [15].

\section{Material And Methods}

\subsection{DESCRIPTION OF THE STUDY AREA}

Two soda lakes, namely, Arenguade/Hora Hadho/ and Chitu were included respectively in this study. As a result of their sensitivity to ecological disturbances, soda lakes are among the ecological systems for which continuous scientific investigations on their microbial diversity should be given high priority [16]. Lake Chitu is located at a distance of about $180 \mathrm{Km}$ South of Addis Ababa at an altitude of $1600 \mathrm{~m}$ above sea level [17]. Likewise, Lake Arenguade is located about $50 \mathrm{Km}$ Southeast of Addis Ababa. For this study, Lake Chitu and Lake Arenguade were thus chosen for their peculiar and interesting features to understand the microbial ecology of the soda lakes in the region. These lakes are similar in that both are crater in origin, have closed basins, have very small catchment areas (limited external material input), and are highly productive. On the other hand, they have several differences. Lake Chitu is shallow (max. depth $17 \mathrm{~m}$ ), located inside the rift valley in semiarid lowland area (1600 m.a.s.I.) and is highly alkaline ( $>600$ $\mathrm{meq} / \mathrm{L}$ ) and saline (>6\%), while Lake Arenguade is deeper (max. depth $32 \mathrm{~m}$ ), located outside the rift valley in the highland area around Bishoftu (2000 m.a.s.l) and is less saline $(<0.3 \%)$ and alkaline (about $50 \mathrm{meq} / \mathrm{L})$. These features are good bases for a comparative microbial community study across sharp environmental gradients [17].

\subsection{Water sample collection}


From each lakes, a total of 12 water samples were collected in $500 \mathrm{~mL}$ sterile screw-capped bottles and sufficient space was provided for aeration and thorough mixing as described in [18]. All samples were labeled and coded as LCHAACC13 (Lake Chitu Alkaliphilic Actinomycetes Culture Collection), LAAACC15 (Lake Arenguade/Hora Hado/ Alkaliphilic Actinomycetes Culture Collection), followed by a specific number to indicate isolate number. Samples were transported to Adama Science and Technology University, Applied Microbiology Laboratory and stored in the refrigerator at $4{ }^{\circ} \mathrm{C}$ until analyzed.

\subsection{Isolation and screening of alkaliphilic actinomycetes}

\subsubsection{Media for the cultivation of actinomycetes}

For the cultivation of actinomycete, both nutrient limiting and nutrient-rich media were used. The isolation media for the two soda lakes were chosen based on the culturability of general actinobacterial and the geochemical properties of the soda lakes [19]. Actinomycete cultures were isolated by serial dilution plating technique on various media including starch casein agar (SCA) composed of ( $\mathrm{g} / \mathrm{l}$ ) soluble starch, 10; Casein ,0.3; $\mathrm{KNO}_{3}$, 2; $\mathrm{NaCl}, 2 ; \mathrm{K}_{2} \mathrm{HPO} 4,2 ; \mathrm{MgSO}_{4} .7 \mathrm{H}_{2} \mathrm{O}, 0.05 ; \mathrm{CaCO}_{3}, 0.02 ; \mathrm{FeSO}_{4} .7 \mathrm{H}_{2} \mathrm{O}, 0.01$; agar, 18; and $\mathrm{Na}_{2} \mathrm{CO}_{3}, 10$; and distilled water, $1,000 \mathrm{ml}$. starch nutrient agar, and Humic Acid agar composed of (g/l) humic acid, $1 ; \mathrm{Na}_{2} \mathrm{HPO}_{4}, 0.5 ; \mathrm{KCl}, 1.71 ; \mathrm{MgSO}_{4} .7 \mathrm{H}_{2} \mathrm{O}, 0.05 ; \mathrm{FeSO}_{4} .7 \mathrm{H}_{2} \mathrm{O}, 0.01 ; \mathrm{CaCO}_{3}, 0.02 ;$ yeast extract, 1 and ; agar, $18 . \mathrm{Na}_{2} \mathrm{CO}_{3}$ was sterilized (at $121^{\circ} \mathrm{C}, 15 \mathrm{psi}$ ) separately as a $25 \%$ solution and added to the rest of the medium after cooling. To inhibit Gram-negative bacterial contamination $1 \mathrm{ml}$ nalidixic acid was added to the medium from a stock solution prepared by dissolving $0.01 \mathrm{~g}$ of nalidixic acid in 10 $\mathrm{ml}$ of $100 \%$ methanol by swirling and mixing in a $37^{\circ} \mathrm{C}$ water bath [19].

\subsubsection{Morphological and biochemical characterization of selected isolates}

Identification of Actinomycetes to the genus level was done by a polyphasic approach, including cultural, morphological, physiological, and biochemical characteristics as described in the International Streptomyces Project Guidelines. The isolation media for the five sites were chosen based on the culturability of general actinobacterial and the geochemical properties of the soda lakes and forest soils. The four media Starch Casein Agar, Starch Casein Broth, Actinomycetes Isolation Agar, and Glycerol Asparagine Agar media were used in combination with temperature $\left(28^{\circ} \mathrm{C}-55^{\circ} \mathrm{C}\right)$, salt $(1-10 \% \mathrm{~W} / \mathrm{v})$ and $\mathrm{pH}(7.0-13)$ ranges to simulate the sampling environment. Glycerol Asparagine Agar media was designed for the isolation of actinomycetes from Chitu and Arenguade soda lakes, whilst the rests are general actinobacterial media.

\subsubsection{Bacterial and Fungal reference strain}


Staphylococcus aureus ATCC25923, S. aureus (clinical isolate) E. coli ATCC 25922, Shigella boydii (clinical isolate), and Fusarium oxysporum f. sp. melonis (CECT 20474), Aspergillus niger, Candida albicans ATCC 62376 and $C$. neoformans (clinical isolates) were used as bacterial and fungal reference (test) strains. The test bacterial and fungal strains were obtained from Ethiopian Health and Nutrition Research Institute (EHNRI) and Biomedical Laboratory, Faculty of Life Sciences, AAU.

\subsection{Media for test microorganisms}

\subsubsection{Nutrient agar and Nutrient broth}

For the antimicrobial susceptibility test and screening, those test bacteria were seeded on nutrient agar media. Twenty-eight grams of nutrient agar (NA) (based on manufacturer's recipe) was dissolved in $1 \mathrm{~L}$ of distilled water and sterilized at $121^{\circ} \mathrm{C}, 15 \mathrm{psi}$. Then about $25 \mathrm{ml}$ of sterile NA media was poured on sterile Petri-dishes and allowed to cool overnight before use. Similarly, $13 \mathrm{~g}$ Nutrient Broth dissolved in $1 \mathrm{~L}$ distilled water and sterilized. About $5 \mathrm{ml}$ of sterile nutrient broth was added on sterile screw-capped test tubes then inoculated with test microorganisms and incubated overnight at $37^{\circ} \mathrm{C}$. The broth culture was adjusted to 0.5 McFarland standards before it was used [19].

\subsubsection{Muller Hinton agar}

For the antibacterial metabolite susceptibility test, thirty-eight grams of Muller Hinton agar based on the manufacturer's recipe were dissolved in $1 \mathrm{~L}$ of distilled water and sterilized at $121^{\circ} \mathrm{C}, 15 \mathrm{psi}$. About $25 \mathrm{ml}$ was poured into sterile Petri dishes to grow the test microorganisms (bacteria).

\subsection{Standardization of inoculum}

Standardization of the inoculum density of isolates for susceptibility test was done by the method described in [20]. To determine the active phase of test organisms, each isolate was grown in $100 \mathrm{~mL}$ of nutrient broth for bacteria and potato dextrose agar for fungi in $250 \mathrm{~mL}$ Erlenmeyer flask on a rotary shaker at $120 \mathrm{r} / \mathrm{min}$ and $37^{\circ} \mathrm{C}$. Samples were taken every $2 \mathrm{~h}$ and the density of the turbidity standard was determined using a spectrophotometer (JENWAY, London) at $660 \mathrm{~nm}$. The optical density values were extra plotted against time to determine the different phases of the growth curve. Samples from the exponential phase were taken to adjust the inoculum density with $0.5 \mathrm{McFarland}$ turbidity standard prepared by adding about $0.05 \mathrm{ml}$ of $1 \% \mathrm{BaCl}_{2}$ and $9.95 \mathrm{ml}$ of $1 \% \mathrm{H}_{2} \mathrm{SO}_{4}$ were mixed to give 0.5 McFarland standards by which approximately $1.5 \times 10^{8}$ bacterial cell suspensions are expected to be present per $\mathrm{ml}$ of culture as cited in [8]. 


\subsection{Primary screening of actinomycetes for antimicrobial activity}

Antimicrobial activity was first screened using the conventional agar cylinders method on Potato Dextrose Agar (PDA) and Muller Hint Agar (MHA) plates for fungi and bacteria respectively [21-22. Mycelium plugs ( $7 \mathrm{~mm}$ diameter) of active isolates incubated at a different time $(3,7,10$, and 14 days) were inoculated onto PDA and MHA plates previously inoculated with target pathogens. Secondly, a double layer method was used for confirmation. The active strain was inoculated as a spot in the center of ISP2 plates at $30^{\circ} \mathrm{C}$ for 7 days. After incubation, the plates were then covered by $10 \mathrm{ml}$ of PDA and MHA previously inoculated with target fungi and bacteria respectively [21]. The inhibition zones around each spot were measured $(\mathrm{mm})$ after $24 \mathrm{~h}$ at $37^{\circ} \mathrm{C}$ for bacteria, $48 \mathrm{~h}$ and 7 days at $30^{\circ} \mathrm{C}$ for yeast and molds respectively. Two replicates were prepared for each test and plates with indicator strain were used as control. The isolates were then selected based on a wide spectrum activity against tested microorganisms for further studies [20].

\subsection{Secondary screening}

The bioactivity testing of the ethanol crude extracts obtained from the selected active isolates was done for antifungal and antibacterial susceptibility based on primary screening results. Minimum inhibitory concentrations of the crude extract was determined for fungus using the protocol described in NCCLS [23] and for bacteria as described in CLSI [20]. All the secondary bioactivity test with crude extracts was conducted in triplicates and inhibition zone diameters were measured.

\section{Data management and analysis}

The collected and recorded data were analyzed using Microsoft Excell. The data on temperature and pH tolerance was analyzed by comparing the mean growth in the log colony forming-unit through analysis of variances (ANOVAs). All statistical results with $\mathrm{P}<0.05$ were considered to be statistically significant.

\section{Results And Discussions}

\subsection{Metabolite production and optimization of selected isolates}

The preliminary antimicrobial activities of the isolates against selected pathogens by the cross streak method showed that they possess antimicrobial properties, as observed from their inhibitory activities against the selected bacterial and fungal strain. From ethanol extracts obtained from Solid State Fermentation (SSF) (Primary screening), a total of 36 isolates of actinomycetes were subjected to primary screening and tested for activity against bacterial and fungal reference strain. Accordingly, the extracts 
from 10 isolates that were most active in the primary screen were 6 (16.66\%) from LCHAACC13 (Lake Chitu Alkaliphilic Actinomycete Culture Collection) that were inhibited the growth of Gram-positive bacteria and fungal strain; 4 (11.11\%) from LAAACC15 (Lake Arenguade Alkaliphilic Actinomycete Culture Collection) that were inhibited Gram-negative bacteria and fungal. From the 10 selected isolates, the best ones in terms of activity spectra were actinomycetes spp. isolated from LCHAACC13. Extracts from 10 isolates that were most active in this primary screen, namely that designated LC-13, LC-15, LC-17, La-13, La-15, Lc-19, Lc-21, La-17, La-19, and Lc-23, were selected for further characterization. Isolates those were coded with Lc-13-23 and La-13, 15, 17, and 19 were obtained from lake Chitu (LC) and Arenguade (La) respectively (Supplementary materials, Table 3 ).

\subsubsection{Dates of incubation period on the production of antibacterial and antifungal metabolite by isolates of two soda lakes}

From evaluated the antibacterial and antifungal potential of two soda lakes water-derived actinomycetes; no antibacterial metabolite production was observed up to 4 and 7 days of incubation for LCHAACC13 (Lake Chitu Alkaliphilic Actinomycete Culture Collection) and LAAACC15 (Lake Arenguade/Hora Hadho/ Alkaliphilic Actinomycete Culture Collection) respectively as shown in figure 1 and 2 below. However, antibacterial and antifungal metabolite production was detected from isolates of LCHAACC13 with maximum zone of inhibition within 5 - 6 days of incubation against Candida albicans ATCC 62376, Aspergillus niger, C. neoformans, Fusarium oxysporum f. sp. melonis (CECT 20474), and Shigella boydii (clinical) (Fig.1). The most resistant test isolates as increasing the time of incubation were Staphylococcus aureus ATCC25923, E. coli ATCC 25922, and S. aureus (clinical isolate). All test microorganisms, except Staphylococcus aureus ATCC25923, E. coli ATCC 25922, and S. aureus (clinical isolate) were sensitive to the culture filtrate starting from 8 - 12 days of incubation and in terms of multiple inhibition and diameter of zone of inhibition, the highest level of antibacterial and antifungal production was obtained at $10^{\text {th }}, 11^{\text {th }}$, and $12^{\text {th }}$ day of incubation by LCHAACC13 and LAAACC 15 respectively (Fig. 1 and 2). Some decrement in activity starting from 13 days of incubation and least activity were observed from 16 days and above.

On the other hand, no strong antibacterial and antifungal metabolite production and activities were observed from LAACC15 (Lake Arengude/Hora Hado/Alkaliphilic Culture Collection) up to 7 days of incubation (Fig.2). However, antimicrobial activity of the culture filtrate of LAACC15 was detected on all test microorganisms except E. coli ATCC 25922, S. aureus ATCC25923, and S. aureus (clinical isolate) starting from the $8^{\text {th }}, 10^{\text {th }}, 11^{\text {th }}$, and $12^{\text {th }}$ days of incubation with maximum and decrement activity at $14^{\text {th }}$ and 16 days onwards respectively (Fig.2). The best antibacterial activity was found against Shigella boydii $(12 \mathrm{~mm})$ clinical isolate, followed by A. niger $(10 \mathrm{~mm}), C$. neoformans (clinical isolate), F. oxysporum f. sp. melonis (CECT 20474), and C. albicans ATCC 62376 (9 mm) (Fig.2). 


\subsubsection{Carbon sources on growth and production of antibacterial and antifungal metabolite by two soda lakes}

Among the carbon sources for the production of antibacterial metabolite by LCHAACC13, high antibacterial and antifungal metabolite production was obtained media containing starch, followed by glycerol, D-xylose, D-glucose, D-fructose, sucrose, and maltose respectively only carbon sources in the submerged fermentation (Fig.3). Interestingly, both strains of soda lakes were unable to use lactose as a sole carbon source. In terms of the effectiveness of the antibacterial activity, the antibacterial metabolite produced from different carbon sources were more effective on $S$. aureus (clinical isolate), A. niger, $C$. neoformans, S. aureus ATCC25923, Fusarium oxysporum f. sp. melonis (CECT 20474), Shigella boydii (clinical isolate) $(12 \mathrm{~mm}$ ) respectively. However, the most resistant test isolate with least activity was detected against Candida albicans ATCC 62376 and E. coli ATCC 25922.

For LAAACC15, high antibacterial and antifungal metabolite production were recorded by the presence of Glycerol, followed by starch, D-xylose respectively (Fig 4). Among tested bacterial reference strains, $S$. aureus ATCC25923, A. niger, C. neoformans and S. aureus (clinical isolate), Fusarium oxysporum $f$. sp. melonis (CECT 20474), Shigella boydii (clinical isolate) $(12 \mathrm{~mm}$ ) were more sensitive. Similarly, like the isolate of lake Chitu, for lake Arenguade the most resistant test isolate with the least activity was detected against Candida albicans ATCC 62376 and E. coli ATCC 25922.

\subsubsection{Nitrogen concentration on growth and production of antibacterial and antifungal metabolite by two soda lakes}

Primary screening of antibacterial metabolite of LCHACC13 from different Nitrogen sources showed that maximum zone of inhibition against Shigella boydii (clinical), Fusarium oxysporum f. sp. melonis (CECT 20474), Aspergillus niger, C. neoformans (clinical isolates), and S. aureus (clinical) in the presence of tryptone, $\mathrm{NaNO}_{3}$, Casein, and $\mathrm{KNO}_{3}$ were used as nitrogen sources respectively, while yeast extract and $\left(\mathrm{NH}_{4}\right)_{2} \mathrm{SO}_{4}$ were least effective in terms of multiple inhibition of the test microorganisms (Fig.5). The most resistant test isolates were Staphylococcus aureus ATCC25923, E. coli ATCC 25922, and Candida albicans ATCC 62376.

The culture filtrate of LAAACC15 grown in different nitrogen sources, however showed very strong antibacterial and antifungal activity against Shigella boydii (clinical), Fusarium oxysporum $f . s p$. melonis (CECT 20474), Aspergillus niger, Candida albicans ATCC 62376 and C. neoformans (clinical isolates) when peptone and $\mathrm{KNO}_{3}$ were used as nitrogen sources and very weak antibacterial and antifungal activity when $\left(\mathrm{NH}_{4}\right)_{2} \mathrm{SO}_{4}$ and $\mathrm{NH}_{4} \mathrm{NO}_{3}$ as nitrogen sources (Fig.6). The most resistant test isolates were Staphylococcus aureus ATCC25923, E. coli ATCC 25922, and S. aureus (clinical).

\subsubsection{Phosphate concentration on growth and production of antibacterial and antifungal metabolite by two soda lakes}


From 12 days culture filtrate of LCHAACC13 grown at different phosphate concentration showed very strong antibacterial and antifungal activity was observed against Candida albicans ATCC 62376, Aspergillus niger, Fusarium oxysporum f. sp. melonis (CECT 20474), Staphylococcus aureus ATCC25923, C. neoformans (clinical isolates), and Shigella boydii (clinical), at the phosphate concentration range between $0.1-0.7 \%$ and maximum activity at $0.2 \%, 0.5 \%$, and $0.6 \%$, whereas when the phosphate concentration was increased to $1 \%$ and above no antibacterial and antifungal metabolite production and activities were reduced (Fig. 7). The most resistant test isolates at all phosphate concentration were $E$. coli ATCC 25922, and S. aureus (clinical).

Antibacterial and antifungal metabolite productions and activities tested from 14 days of culture filtrate of LAACC15 showed very strong antibacterial and antifungal activity was observed against Shigella boydii (clinical), Aspergillus niger, Fusarium oxysporum f. sp. melonis (CECT 20474), S. aureus (clinical), C. neoformans (clinical isolates), and Shigella boydii (clinical), at the phosphate concentration range 0.1 $1 \%$ and maximum activity at $0.5 \%$ and $0.6 \%$, whereas when the phosphate concentration was increased to $3 \%$ and above antibacterial and antifungal metabolite production and activities were reduced (Fig. 8). The most resistant test isolates at all phosphate concentration were E. coli ATCC 25922, Staphylococcus aureus ATCC25923, and Candida albicans ATCC 62376.

\subsubsection{Salt concentration on growth and production of antibacterial and antifungal metabolite by two soda lakes}

Extracted CF of LCHAACC13 showed very strong antibacterial and antifungal activity was observed against $C$. neoformans (clinical isolates), Aspergillus niger, $S$. aureus (clinical), Candida albicans ATCC 62376, and Fusarium oxysporum $f$. sp. melonis (CECT 20474), at the salt concentration range 0.1 - 5\% and maximum activity at $0.5 \%$. On the other hand, weak antibacterial and antifungal activity was detected from the crude filtrate of isolates grown on $3 \%, 5$, and $7 \% \mathrm{NaCl}$ concentration and no antibacterial metabolite from the isolates grown without $\mathrm{NaCl}$ (Fig. 9). The most resistant test isolates at all salt concentration were E. coli ATCC 25922, Staphylococcus aureus ATCC25923, and Shigella boydii (clinical).

On the other hand, extracted crude filtrate of LAACC15 showed very strong antibacterial and antifungal activity against $C$. neoformans (clinical isolates), Aspergillus niger, $S$. aureus (clinical), Candida albicans ATCC 62376, and Fusarium oxysporum f. sp. melonis (CECT 20474), at the salt concentration range $0.1-3 \%$ and maximum activity at $1 \%$. Unlike the crude filtrate of lake Chitu, no antibacterial and antifungal activity was detected from the crude filtrate of the isolates grown on $3 \%, 5$, and $7 \% \mathrm{NaCl}$ concentration and no antibacterial metabolite from isolates grown without $\mathrm{NaCl}$ (Fig. 10). The most resistant test isolates at all salt concentration were E. coli ATCC 25922, Staphylococcus aureus ATCC25923, and Shigella boydii (clinical). 


\subsubsection{Effect of pH on growth and antibiotic production by LCHAACC 13 and LAAACC 15}

The final $\mathrm{pH}$ measured for both isolates grown on different cultivation media indicated that the $\mathrm{pH}$ remained alkaline regardless of the medium constituents and for both isolates antibacterial and antifungal metabolite production was more favored when the $\mathrm{pH}$ of the cultivation media adjusted between $9-11$, with maximum activity at 10 against $C$. neoformans (clinical isolates), Aspergillus niger, $S$. aureus (clinical), Candida albicans ATCC 62376, and Fusarium oxysporum f. sp. melonis (CECT 20474). The most resistant test isolates at all salt concentration was E. coli ATCC 25922, Staphylococcus aureus ATCC25923, and Shigella boydii (clinical). As shown in figure 11 for both isolates production of antibacterial metabolite was favored when the culture condition was alkaline and both culture filtrate of LCHAACC13 and LAACC 15 was stable at alkaline $\mathrm{pH}$ but weak stability at $\mathrm{pH} 12$ and unstable at $\mathrm{pH} 13$ values.

\subsubsection{Effect of cultural temperature and growth period}

It was observed that the crude filtrate of LCHAACC13 and LAAACC 13 were stable from $40{ }^{\circ} \mathrm{C}-60{ }^{\circ} \mathrm{C}$ with maximum activity at $40^{\circ} \mathrm{C}$. against $E$. coli and $S$. aureus ATCC25923.

\section{Discussions}

From the finding, we observed that growth, antibacterial, and antifungal metabolite production and activities by isolates were positively affected by seven independent variables, namely incubation period, carbon (starch), nitrogen $\left(\mathrm{NaNO}_{3}\right.$, Casein, and $\left.\mathrm{KNO}_{3}\right)$ sources, phosphate concentrations, $\mathrm{pH}$, salt concentration, and temperature stability. We evaluated in vitro antibacterial and antifungal potential of two soda lakes water-derived actinomycetes and we observed that no strong antibacterial and antifungal metabolite production up to 4 and 7 days of incubation for lake Chitu alkaliphilic actinomycete culture collection and lake Arenguade/Hora Hadho/ alkaliphilic actinomycete culture collection)

respectively. However, from isolates of LCHAACC13, we observed that with a maximum zone of inhibition within 5 - 6 days of incubation against Candida albicans ATCC 62376, Aspergillus niger, C. neoformans, Fusarium oxysporum $f$. sp. melonis (CECT 20474), and Shigella boydii (clinical) (Fig.1). The most resistant test isolates as increasing the time of incubation were Staphylococcus aureus ATCC25923, E. coli ATCC 25922, and S. aureus (clinical isolate). All test microorganisms, except Staphylococcus aureus ATCC25923, E. coli ATCC 25922, and S. aureus (clinical isolate) were sensitive to the culture filtrate starting from 8 - 12 days of incubation and in terms of multiple inhibition and diameter of zone of inhibition, the highest level of antibacterial and antifungal production was obtained at $10^{\text {th }}, 11^{\text {th }}$, and $12^{\text {th }}$ day of incubation by LCHAACC13 and LAAACC15 respectively.

Some decrement in activity starting from 13 days of incubation and least activity were observed from 16 days and above. Our result is in agreement with [24], they evaluated the antimicrobial activity of the strain 
ActiF450 against selected $S$. aureus and observed that antimicrobial activity started after 2 days of incubation and reached a maximum after 7 days. They observed a potent and broad-spectrum activity against a range of human fungal pathogens including moulds and yeasts, such as Arthroderma vanbreuseghemii, A. fumigatus, A. niger, C. albicans, C. glabarta, C. krusei, C. parapsilosis, F. oxysporum, F. solani, Microsporum canis, Rhodotorula mucilaginous and Scodapulariopsis candida. In addition, high antibacterial activity was recorded against pathogenic staphylococci. [25] screened 180 actinobacteria for their novel biocontrol agents against plant pathogens for anti-fungal activity both in vitro and in vivo and found that three isolates exhibited potent anti-fungal activity against Botrytis cinerea and $F$. oxysporum f. sp. cucumerinum evaluated antifungal activity of Streptomyces rimosus MY02 [26] and observed the diameter of inhibition zone of the culture supernatant from S. rimosus MY02 against Fusarium oxysporium $\mathrm{f} \mathrm{sp}$. cucumarinum was $33.19 \mathrm{~mm}$.

The results showed that among the carbon sources antibacterial and antifungal activity was higher when the isolate was grown in a medium having starch casein agar for lake Chitu isolates enhanced the production of secondary metabolites and the zone of inhibition against reference bacterial and fungal strain which is in agreement with [27-28] that starch casein medium found to be good base for antibacterial and antifungal metabolite production and D-xylose for lake Arenguade in agreement with [29] dextrose prove to be the best carbon source for antibiotic production by $S$. kanamyceticus M27 with a maximum zone of inhibition $(22 \mathrm{~mm}$ ) and $19 \mathrm{~mm}$ respectively. Our result is also supported by [30-33] that they concluded that the rate at which carbon source is metabolized can influence the formation of biomass or production of primary or secondary metabolites and fast growth due to high concentrations of rapidly metabolized sugars is often associated with low productivity of secondary metabolites.

Other researchers namely, [8] soybean meal proved to be a suitable carbon source for antibiotic production by $S$. tanashiensis $\mathrm{A}_{2} \mathrm{D}$; [34] no secondary metabolite production with supplemented medium with galactose, lactose, raffinose, and maltose as a sole carbon source; [35] readily metabolized carbon sources, such as glucose, can suppress antibiotic production by preventing the synthesis of a key enzyme in the biosynthesis pathway referred to as "catabolic repression"; $[29,35,36] S$.

griseocarneus, Streptomyces violatus, and S. sannanensis strain RJT-1, glucose found to be suitable carbon source for the antibiotic production; while dextrose at a concentration of $2 \mathrm{~g} / 100 \mathrm{ml}$ gave maximal antibiotic titers and a higher dose decreased the yield by $S$. kanamyceticus[29;34] high concentration of glucose as a repressor of secondary metabolisms and maximum cell growth rates can inhibit antimicrobial agent production[33]. An example of catabolic repression of secondary metabolism in actinomycetes is that of actinomycin synthesis by $S$. antibioticus after more glucose is added to the media [37] and in S. aureofaciens, the production of tetracycline was critically influenced when $10 \%$ soluble starch was enriched with sweet potato residues [38].

Among the nitrogen sources used for the isolate of LCHAACC13 (Fig. 6), yeast extract was suitable in higher production of antibacterial metabolites that were active against $E$. coli and $S$. aureus followed by $\mathrm{NaNO}_{3}$, casein, and $\mathrm{KNO}_{3}$ that were effective against most of the test bacteria (Table.10). The culture 
filtrate of LAAACC15 grown in different nitrogen sources was showed that very weak antibacterial activity against Shigella boydii as compared to the antibacterial activity obtained from the usual cultivation media starch casein agar (SCA) which contains a combination of Casein and $\mathrm{KNO}_{3}$ as nitrogen sources (Fig. 6). This might because yeast extract is rich in vitamins, minerals, amino acids, digested nucleic acids, and other growth factors which could induce antibacterial metabolite synthesis. The results are comparable with [36] as they observed yeast extract gave the highest antimicrobial metabolite production followed by $\mathrm{NaNO}_{3}$, peptone, and $\mathrm{KNO}_{3}$ by new Streptomyces species; [29] in which they tested different nitrogen source contained the basal mineral salts plus $2 \%$ dextrose and amino acids and inorganic nitrogen compounds employed at a concentration equivalent to $84 \mathrm{mg}$ of nitrogen per $100 \mathrm{ml}$. They obtained the highest antibiotic in a synthetic medium containing $\left(\mathrm{NH}_{4}\right) \mathrm{H}_{2} \mathrm{PO}_{4}$ as the nitrogen sources and the optimal concentration for antibiotic production at a concentration of $0.68 \%$.

Additionally,[18], in the production of polyene antibiotics, soybean meal has been considered as a good nitrogen source because of the balance of nutrients, low phosphorous content, and slow hydrolysis and concluded that the presence of nitrogen regulation revealed on the enzymatic level in the fermentation of cephamycin and patulin [39] observed that higher growth and antibacterial activity in ammonium nitrate as nitrogen source followed by sodium nitrate and potassium nitrate exhibited maximum growth and antibacterial activity [40] investigated the effects of nitrogen sources on streptolydigin production and distribution of secondary metabolites from Streptomyces lydicus. They found that when soybean meal was used as the source of nitrogen, three analogs of streptolydigin were detected, and among the nitrogen sources glutamic acid was most favorable for the formation of streptolydigin.

Antibacterial and antifungal metabolite production were tested from 12 days culture filtrate of LCHAACC13 grown at different phosphate concentration and the result showed that detectable activity was observed at the phosphate concentration range between $0.1-0.7 \%$ and maximum activity at $0.2 \%$, whereas when the phosphate concentration was increased to $1 \%$ and above no antibacterial metabolite production (Fig. 8 and 9). It has been reported that phosphate concentrations above $0.005 \%$ suppress production of natamycin by Streptomyces natalensis [41; 42] that $\mathrm{KH}_{2} \mathrm{PO}_{4}$ is not favorable for the production of antibiotic by $\mathrm{S}$. violatus, however, $\mathrm{K}_{2} \mathrm{HPO}_{4}$ at a concentration of $1 \mathrm{~g} / \mathrm{l}$ yields an inhibition zone of $22 \mathrm{~mm}$, equivalent to an antibiotic concentration of $128 \mu \mathrm{g} / \mathrm{ml}$. Elucidation of the precise interaction between phosphate metabolism and antibiotic biosynthesis has been complicated by the fact that phosphate is involved in a host of related and non-related metabolic pathways [43].

In addition, [44] also found that when adding a large amount of inorganic phosphate, consumption of carbon and nitrogen sources and respiration are accelerated resulting in good growth, but the production of antibiotics is usually reduced. However, it is presumed that when the concentration of inorganic phosphate in the culture is high, the intracellular concentration of ATP is increased and the primary metabolism is accelerated. When the amount of inorganic phosphate is lowered, the ATP concentration decreases; this decrease depresses metabolic conversions which are required for the production of antibiotics [43]. In general, three separate regulatory roles, viz. independently inhibition of enzyme action, regulation of protein expression, and limit on the cell growth have been postulated for phosphate [43]. 
For both isolates, antibacterial and antifungal metabolite production was more favored when the $\mathrm{pH}$ of the cultivation media adjusted between $9-11$, with maximum activity at 11 for lake Chitu and 10 Arenguade respectively. The results are comparable with alkaliphilic actinomycetes Nocardiopsis alkaliphila sp. nov. [45, 46] grow optimally at pH $9.5-10$. N. metallicus [47] exhibited growth in the $\mathrm{pH}$ range 7-10.5, whereas in Bogoriella caseilytica [48], a new alkaliphilic actinomycete, optimum growth occurred at $\mathrm{pH}$ values 9-10. The results are comparable with some Streptomyces species recorded to produce antibiotics against bacteria, fungi, and yeast at alkaline $\mathrm{pH}$ [8]. The results are in contrast to the result reported using Streptomyces sp. for antimicrobial production [49]. Our finding supports the fact that generally, alkaline environment is more suitable for the growth of Streptomyces and thus production of antimicrobial compound $[50 ; 51]$ reported that when the $\mathrm{pH}$ was maintained at 5 , production of geldanamycin was increased from 414 to $768 \mathrm{mg} / \mathrm{L}$. [51] studied the effects of the temperature, $\mathrm{pH}$, incubation period, for the production of antimicrobial metabolite production and they found temperature of $35^{\circ} \mathrm{C}$ and $\mathrm{pH} 8$ were the best for growth and antimicrobial agent production and 14 to 15 days of incubation was found to be the best for maximum growth and antimicrobial activity, respectively.

An Increase in the concentration of sodium chloride in the medium influenced the growth and antimicrobial compound production. Extracted CF of LCHAACC13 showed that maximum antibacterial metabolite production at $1 \%$ salt concentration against Salmonella typhii and Streptococcus Pneumonia, whereas, Escherichia coli and Pseudomonas aeruginosa as shown in Figure 10 below. On the other hand, weak antibacterial and antifungal activity was detected from the crude filtrate of both isolates grown on $5 \%, 7 \%$, and $9 \% \mathrm{NaCl}$ concentration and no antibacterial metabolite from both isolates grown without $\mathrm{NaCl}$. [18] reported the antimicrobial potential of actinomycetes to isolate that grew in the presence of $20 \%(\mathrm{w} / \mathrm{v}) \mathrm{NaCl}$, while antibiotic production being maximum with $5 \%(\mathrm{w} / \mathrm{v}) \mathrm{NaCl}$ in the production medium. [52] reported that good growth as well as an antimicrobial activity when salt concentrations of $12 \mathrm{~g} / \mathrm{L}$ and a decline in growth and antimicrobial activity after $20 \mathrm{~g} / \mathrm{L}$. In Streptomyces fradiae NCIM 2418 [53], neomycin production was enhanced by sodium nitrate and ammonium chloride, copper sulphate, and zinc sulphate positively influenced on neomycin production. In Streptomyces rimosus [54], supplementation of $1 \%(\mathrm{w} / \mathrm{w}) \mathrm{CaCO}_{3}$, enhance the production of tracycline in solid state fermentation when corncob was used as the solid medium.

Usually, cultivation for antibiotic production is performed under one constant temperature from the beginning to the end, but the temperature adequate for growth is not always the same as that for production. It is known that thermophilic actinomycetes such as thermo actinomycetes produce new antibiotics at a temperature higher than $40^{\circ} \mathrm{C}$, but Streptomyces usually produces antibiotics at temperatures near $27^{\circ} \mathrm{C}$. Generally, the range of a temperature supporting good growth is as wide as 25 ${ }^{\circ} \mathrm{C}$, but the temperature range adequate for good production of secondary metabolites is narrow and $5 \sim$ $25^{\circ} \mathrm{C}$ [35]. S. violates showed a narrow range of incubation temperature for relatively good growth and antibiotic production. The increase of the incubation temperature from $20^{\circ} \mathrm{C}$ to $30^{\circ} \mathrm{C}$, increased the growth of the cells and the production of the antibiotic by 3.45-fold and 4.39-fold, respectively. Maximum antibiotic production was obtained at $30^{\circ} \mathrm{C}$. A higher incubation temperature $\left(35^{\circ} \mathrm{C}\right)$ harmed growth and 
antibiotic production. The size of inoculum affected the ability of $S$. violates to produce the antibiotic in the tested cultures. An increase of the inoculum size from $0.5 \mathrm{ml}$ to $2 \mathrm{ml} / 50 \mathrm{ml}$ medium enhanced the production of the antibiotic by approximately 4.6 - fold. Thus temperature must be considered separately growth and for production. It would be of interest in antibiotic screening to use temperature shifts [41].

\section{Conclusion}

The present study provides evidence that Ethiopian Soda lakes are a rich and valuable resource of potentially active actinomycetes. Concisely, this study highlighted for the first time the antimicrobial potentials of soda lakes associated actinobacteria with the ability to suppress major human fungal and bacterial pathogens in vitro. Further studies are needed to enhance the isolation and selection of actinomycetes from unexplored ecosystems for antibiotic discovery. Hopefully, these new agents will meet the challenges as we attempt to manage serious underlying infectious diseases. In addition, knowledge of the actinobacteria gene clusters may provide important answers toward understanding the metabolites biosynthetic pathway.

\section{Declarations}

\section{Disclosure of interest}

The authors declare no conflicts of interest regarding the publication of this study.

\section{Funding sources}

This research did not receive any specific grant from funding agencies in the public, commercial, or notfor-profit sectors.

\section{Tables}

Table.1. Preliminary antimicrobial screening of 10 active isolates against different microbial pathogens.

\begin{tabular}{|l|l|l|l|l|l|l|l|l|l|l|l|}
\hline & \multicolumn{9}{|c|}{ Active isolates } \\
& \multicolumn{9}{|c|}{ Pathogens } & \multicolumn{9}{|c|}{} & Lc-13 & Lc-15 & Lc-17 & La-13 & La-15 & Lc-19 & Lc-21 & La-17 & La-19 & Lc- 23 \\
\hline S. aureus ATCC25923 & ++ & ++ & ++ & ++ & ++ & ++ & ++ & ++ & ++ & ++ \\
\hline S. aureus (clinical) & +++ & +++ & +++ & +++ & +++ & +++ & +++ & +++ & +++ & +++ \\
\hline E. coli ATCC 25922 & ++ & ++ & ++ & ++ & ++ & ++ & ++ & ++ & ++ & ++ \\
\hline Sh. boydii (clinical) & +++ & +++ & +++ & +++ & +++ & +++ & +++ & +++ & +++ & +++ \\
\hline F. oxysporum (CECT 20474) & +++ & +++ & +++ & +++ & +++ & +++ & +++ & +++ & +++ & +++ \\
\hline Aspergillus niger & +++ & +++ & +++ & +++ & +++ & +++ & +++ & +++ & +++ & +++ \\
\hline C. albicans ATCC 62376 & ++ & ++ & ++ & ++ & ++ & ++ & ++ & ++ & ++ & ++ \\
\hline C. neoformans (clinical) & +++ & +++ & +++ & +++ & +++ & +++ & +++ & +++ & +++ & +++ \\
\hline
\end{tabular}


+++: Good activity; ++: Moderate activity; +: Weak activity; -: No activity.

Table.2. Secondary antimicrobial screening of 10 active isolates against different microbial pathogens.

\begin{tabular}{|c|c|c|c|c|c|c|c|c|c|c|c|}
\hline \multirow[t]{2}{*}{ Pathogens } & & \multicolumn{10}{|c|}{ Active isolates (zone of inhibition in $\mathrm{mm}$ ) } \\
\hline & $\mathrm{C}$ & $\begin{array}{l}\text { LC- } \\
13\end{array}$ & $\begin{array}{l}\text { LC- } \\
15\end{array}$ & $\begin{array}{l}\text { LC- } \\
17\end{array}$ & $\begin{array}{l}\mathrm{La}^{-} \\
13\end{array}$ & $\begin{array}{l}\text { La- } \\
15\end{array}$ & $\begin{array}{l}\text { LC- } \\
19\end{array}$ & $\begin{array}{l}\text { LC- } \\
21\end{array}$ & $\begin{array}{l}\text { La- } \\
17\end{array}$ & $\begin{array}{l}\mathrm{La}^{-} \\
19\end{array}$ & Lc-23 \\
\hline S. aureus ATCC 25923 & 14 & 10 & ++ & ++ & ++ & ++ & ++ & ++ & ++ & ++ & ++ \\
\hline S. aureus (clinical) & 14 & 12 & +++ & +++ & +++ & +++ & +++ & +++ & +++ & +++ & +++ \\
\hline E. coli ATCC 25922 & & ++ & ++ & ++ & ++ & ++ & ++ & ++ & ++ & ++ & ++ \\
\hline Sh. boydii (clinical) & & +++ & +++ & +++ & +++ & +++ & +++ & +++ & +++ & +++ & +++ \\
\hline $\begin{array}{ll}\text { F. oxysporum (CECT } \\
\text { 20474) }\end{array}$ & & +++ & +++ & +++ & +++ & +++ & +++ & +++ & +++ & +++ & +++ \\
\hline Aspergillus niger & 14 & +++ & +++ & +++ & +++ & +++ & +++ & +++ & +++ & +++ & +++ \\
\hline C. albicans ATCC 62376 & 13 & ++ & ++ & ++ & ++ & ++ & ++ & ++ & ++ & ++ & ++ \\
\hline C. neoformans (clinical) & & +++ & +++ & +++ & +++ & +++ & +++ & +++ & +++ & +++ & +++ \\
\hline
\end{tabular}

C-Control (Streptomycin for bacteria; ketoconazole for fungi)

\section{References}

[1] Barka EA, Vatsa P, Sanchez L (2016) Taxonomy, physiology, and natural products of the Actinobacteria. Microbiology Molecular Biology Review 80: 1-43.

[2] Kumar M.S., Das, A.P. (2016) Molecular identification of multi drug resistant bacteria from urinary tract infected urine samples. Microbial. Pathogen 98:37 - 44.

[3] Katz, L, and Baltz, R. H (2016) Natural product discovery: past, present, and future. J Microbiology and Biotechnology 43:155 - 176. Doi:10.1007/s10295-015 17235.

[4] Van der Meij A, Worsley S. F, Hutchings M. I, and van Wezel G. P (2017) Chemical ecology of antibiotic production by actinomycetes. FEMS Microbiology Review 41: 392 - 416.doi:10.1093/femsre/fux005.

[5] Avinash T. S, and Ravishankar, R. V (2017) Bio-control of Fusarium wilt disease of Cucumber (Cucumissativus L.) in Greenhouse and Field. International Journal of Agricultural Technology, 13(4): 531 - 543. http://www.ijat-aatsea.com_ISSN 2630-0192.

[6] Pathalam G, Appadurai DR, Rajendran Host A, Munusamy R, Michael G, Naif A, Savarimuthu I (2017) Antimicrobial activity of some Actinomycetes from Western Ghats of Tamil Nadu. Alexandria Journal of Medicine 53:101-110. 
[7] BBC. (2018) The lists of WHO a danger that pharmaceutical companies will develop only treatments that are easier and more profitable to make.

[8] Singh S, Mazumder T.C, Bora (2009) Optimization of process parameters for growth and bioactive metabolite produced by a salt-tolerant and alkaliphilic actinomycete Streptomyces tanashiensis strain A2D. Journal of Medical Mycology 19: 225 - 233.

[9] Govindan R, Govindan R, Muthuchamy M, Baskaralingam V, Natesan M (2019) Molecular identification andstructural characterization of marine endophytic actinomycetes Nocardiopsis sp. GRG 2 (KT 235641) and its antibacterial efficacy. Bioactive materials 1:140 - 150.

[10] Biniam W (2008) Bioactive compounds from alkaliphilic actinomycetes, Department of Biology (Microbiology). Addis Ababa University Unpublished.

[11] Daniel Mehabie (2011) Antibiotic production and optimization of culture condition of Actinomycetes from some soda lakes of Ethiopia. Addis Ababa University, Ethiopia, Unpublished.

[12] Gebreselema Gebreyohannes, Samuel Sahile, Feleke Moges, and Nagappan R (2013) Isolation and characterization of potential antibiotic producing actinomycetes from water and sediments of Lake Tana. Asian Pacific Journal of Tropical Biomedicine 3(6): 426 - 435.

[13] Atsede Muleta and FassilAssefa (2018) Isolation and screening of antibiotic producing actinomycetes from rhizosphere and agricultural soils. African Journal of Biotechnology 17 (22):700 714.

[14]Abebe Bizuye, Feleke Moges, Berhanu Andualem (2013) Isolation and screening of antibiotic producing Actinomycetes from soils in Gondar town, North West Ethiopia. Asian Pacific Journal of Tropical Disease 3(5): 375 - 381.

[15] Kibret M, Guerrero JF,Urban E, Wronski V-K., Busche T, Rollinger JM, Abate D and Zotchev SB (2018) Streptomyces spp. from Ethiopia producing antimicrobial compounds: Characterization via bioassays, genome analyses, and MS. Frontier Microbiology, 9:1270.doi: 10.3389/fmicb.2018.01270.

[17] Elizabeth Kebede (1997) Response of Spirulina platensis (Arthrospira fusiformis) to salinity stress from sodium salts from Lake Chitu, Ethiopia. J Appl. Phyco 9: 551 - 558.

[18] Saha M.R, Ripa F.A, Islam M.A. and Khondkar P (2010) Optimization of Conditions and in vitro Antibacterial Activity of Secondary Metabolite Isolated from Streptomyces sp. MNK7. Journal of Applied Sciences Research',6(5): pp. 453-459.

[19] Duckworth AW, Grant S, Grant WD, Jones BE, Meijer D (1998) Dietzia natronolimnaios,sp. nov., a new member of the genus Dietzia isolated from an East African soda lake. Extremophiles, 2: $359-366$. 
[20] CLSI. (2012) Performance standards for antimicrobial disk susceptibility tests and approved Standard. $7^{\text {th }}$ Ed. CLSI document M02-A11. Wayne, PA: Clinical and Laboratory Standards Institute.

[21] Bharti, A, Kumar V, Gusain, O, and Bisht G. S (2010). Antifungal activity of actinomycetes isolated from Garhwal Region. J. Sci. Eng. Tech. Mgt. 2:1- 7.

[22] Benhadj M, Gacemi-Kirane D, Menasria T, Guebla K, Ahmane Z (2019) Screening of rare actinomycetes isolated from natural wetland ecosystem (Fetzara Lake, north-eastern Algeria) for hydrolytic enzymes and antimicrobial activities. J King Saud Univ Sci. 31: 706- 12.

[23] NCCLS (2002) Reference Method for Broth Dilution Antifungal Susceptibility Testing of Yeasts; Approved Standard, 2nd Edn. Pennsylvania: NCCLS document M27-A2.

[24] Mabrouka Benhadj, Roumaisa Metrouh, Taha Menasria, Djamila Gacemi-Kirane, Fatma Zohra Slim, Stephane Ranque (2020) Broad-spectrum antimicrobial activity of wetland-derived Streptomyces sp. ActiF450 EXCLI Journal 19: 360 - 371 - ISSN 1611-2156.

[25] Xi Wang, Manrang Zhang, Jiangtao Gao, Taixun Pu, Muhammad Bilal, Yonghong Wang, Xing Zhang (2018) Anti-fungal activity screening of soil actinobacteria isolated from Inner Mongolia, China. Biological Control, 127: $78-84$.

[26] Jicheng Yu, Qiu Liu, Qiao Liu, Xiangdong Liu, Qiang Sun, Jianfang Yan, Xiaohui Qi, Shengdi Fan (2009) Effect of liquid culture requirements on antifungal antibiotic production by Streptomyces rimosus MY02. Bio-resource technology 99: 2087 - 2091.

[27] Arumugam P, Senthil Kumar R, Kameshwar K, Prapanchana (2017) Screening of novel actinobacteria and characterization of the potential isolates from mangrove sediment of south coastal India. Microbial Pathogenesis 107: 225 - 233.

[28] Vilches C, Mendez C, Hardisson C, Salas JA (1990) Biosynthesis of oleandomycin by Streptomyces antibioticus: influence of nutritional conditions and development of resistance. Journal of General Microbiology 136:1447-1454.

[29] Pandey A, Shukla A, Majumdar SK (2005) Utilization of carbon and nitrogen sources by Streptomyces kanamyceticus M 27 for the production of an antibacterial antibiotic. African Journal of Biotechnology 4: $909-10$.

[30] Houssam M. Atta (2015) Biochemical studies antibiotic production from Streptomyces species. Journal of Saudi Chemical Society, 19: pp. $12-22$.

[31] Grant WD (2006) Alkaline environments and biodiversity, in Extremophilies, Eds. Charles Gerday, and Nicolas Glansdorff, in Encyclopedia of Life Support Systems (EOLSS), Developed under the Auspices of the UNESCO, Eolss Publishers, Oxford ,UK, http://www.eolss.net. 
[32] Calvo AM, Wilson RA, Bok JW, Keller NP (2002) Relationship between secondary metabolism and fungal development. Microbiol Mol Biol Rev 66: 447 - 459.

[33] Ripa F. A, Nikkon F, Zaman S. and Khondkar, P (2009) Optimal conditions for antimicrobial metabolites production from a new Streptomyces sp. RUPA-08PR isolated from Bangladeshi soil. Mycobiology 37(3): 211-214.

[34] Balachandara N, Karmegam M, Saravanan R, Subbaiya P, Gurumoorthy (2018) Synthesis of bioactive compounds from vermicast isolated actinomycetes species and its antimicrobial activity against human pathogenic bacteria. Microbial Pathogenesis 121: 155-165.

[35] Maha A. Hassan, Moustafa Y. El-Naggar and Wafa Y. Said (2016) Physiological factors affecting the production of an antimicrobial substance by Streptomyces violatus in batch cultures. Egyptian Journal of Biology 3: $1-10$.

[36] Cruz R, Arias ME, Soliveri J (1999) Nutritional requirements for the production of pyrazoloisoquinolinone antibiotics by Streptomyces griseocarneus NCIMB 40447. Appl Microbiol Biotechnol 53: 115 - 119.

[37] Drew SW, Demain AL (1977) Effects of primary metabolites on secondary metabolism. Ann Rev Microbiol 31: 343 - 356.

[38] Yang S.S, Ling M.Y (1989) Tetracycline production with sweet potato residue by solid-state fermentation. J. Biotechnol. Bioeng 33: 1021-1028.

[39] Mariadhas Valan Arasu, Thankappan Sarasam Rejiniemon, Naif Abdullah Al-Dhabi, Veeramuthu Duraipandiyan, Savarimuthu Ignacimuthu, Paul Agastian, Sun-Ju Kim, V. Aldous J. Huxley, Kyung Dong Lee, Ki Choon Choi (2014) Nutritional requirements for the production of antimicrobial metabolites from Streptomyces. African Journal of Microbiology Research (8): 750-758.

[40] Liangzhi LI, Bin Q, Yingjin Y (2007) Nitrogen sources affect strep-tolydigin production and related secondary metabolites distribution of Streptomyces lydicus. Chin. J. Chem. Eng. 15: $403-410$.

[41] Hesham A, EL-Enshays, Mohammed A, Farid and El-Sayed A (2000) Influence of inoculum type and cultivation conditions on natamycin production by Streptomyces natalensis. J. Basic Microbiol. 40: $333-$ 342.

[42] Mabrouka Benhadj, Djamila Gacemi-Kirane, Taha Menasria, Khaoula Guebla, Zina Ahmane (2019) Screening of rare actinomycetes isolated from natural wetland ecosystem (Fetzara Lake, northeastern Algeria) for hydrolytic enzymes and antimicrobial activities. Journal of King Saud University $31: 706-712$.

[43] Martin JF (1977) Control of antibiotic synthesis by phosphate. In: Ghose TK, Fiechter A, Blakebrough $\mathrm{N}$ (eds) Advances in biochemical engineering. Springer, Berlin, $105-127$. 
[44] Lamenew Fenta (2017) Isolation and characterization of phosphate solubilizing bacteria from tomato (Solanum I.) rhizosphere and their effect on growth and phosphorus uptake of the host plant under greenhouse experiment. International Journal of Advanced Research, ISSN 23205407,http://www.journalijar.com.

[45] Kim YJ, Song JY, Moon MH, Smith CP, Hong SK, Chang YK (2007) pH shock induces overexpression of regulatory and biosynthetic genes for actinorhodin production in Streptomyces coelicolor A3(2). Appl. Microbiol. Biotechnol. 76:1119-1130.

[46] Wael NH, Wen-Jun L, Mohammed IA, Hammouda O, Ahmed SM, Li-Hua Xu (2004) Nocardiopsis alkaliphila sp. nov., a novel alkaliphilic actinomycetes isolated from desert soil in Egypt; International Journal of Systematic Evolutionary Microbiology 54: 247-252.

[47] Schippres A, Bosecker K, Willscher S, Sproer C, Schumann P, Kroppenstedt RM (2002) Nocardiopsis metallicus sp. nov., a new metal-leaching actinomycetes isolated from an alkaline slag dump. International Journal of Systematic Evolutionary Microbiology 52:2291-2295.

[48] Groth I, Schumann P, Rajney FA, Martin K, Schueteze B, Augsten K (1997) Bogoriella caseilytica gen. nov., sp. nov., a new alkaliphilic actinomycetes from a soda lake in Africa. Intern $\mathrm{J}$ of Systematic Evolutionary Microbiology 47: $788-794$.

[49] Arasu V, Duraipandiyan P, Agastian S, Ignacimuthu (2009) In vitro antimicrobial activity of Streptomyces spp., ERI-3 isolated from Western Ghats rock soil (India), J. Mycol. Méd.

19: 2228.

[50] Yilmaz M, Yavuz M, Kizil (2008) Molecular characterization of rhizospheric soil Streptomycetes isolated from indigenous Turkish plants and their antimicrobial activity. World J. Microbiol. Biotechnol 24: 1461-1470.

[51] Nadia HN, Abdel FM, Khaleafa SHZ (2004) Factors affecting anti-microbial activity of Synechococcus leopoliensis. Microbiol. Res. 159: 395 - 402.

[52] Vasavada SH, Thumar JT, Singh SP (2006) Secretion of a potent antibiotic by salt-tolerant and alkaliphilic actinomycete Streptomyces sannanensis strain RJT-1. Curr Sci 91:1393-1397.

[53] Vastrad, B.M., Neelagund, S.E., 2014. Optimization of medium composition for the production of neomycin by Streptomyces fradiae NCIM 2418 in solid state fermentation; Biotechnology Research International, 11 Article ID, 674286.

[54] Yang S.S, Swei W.J (1996) Cultural condition and oxytetracycline production by Streptomyces rimosus in solid state fermentation of corncob. World J. Microbiol. Biotechnol. 12: 43-46.

\section{Figures}




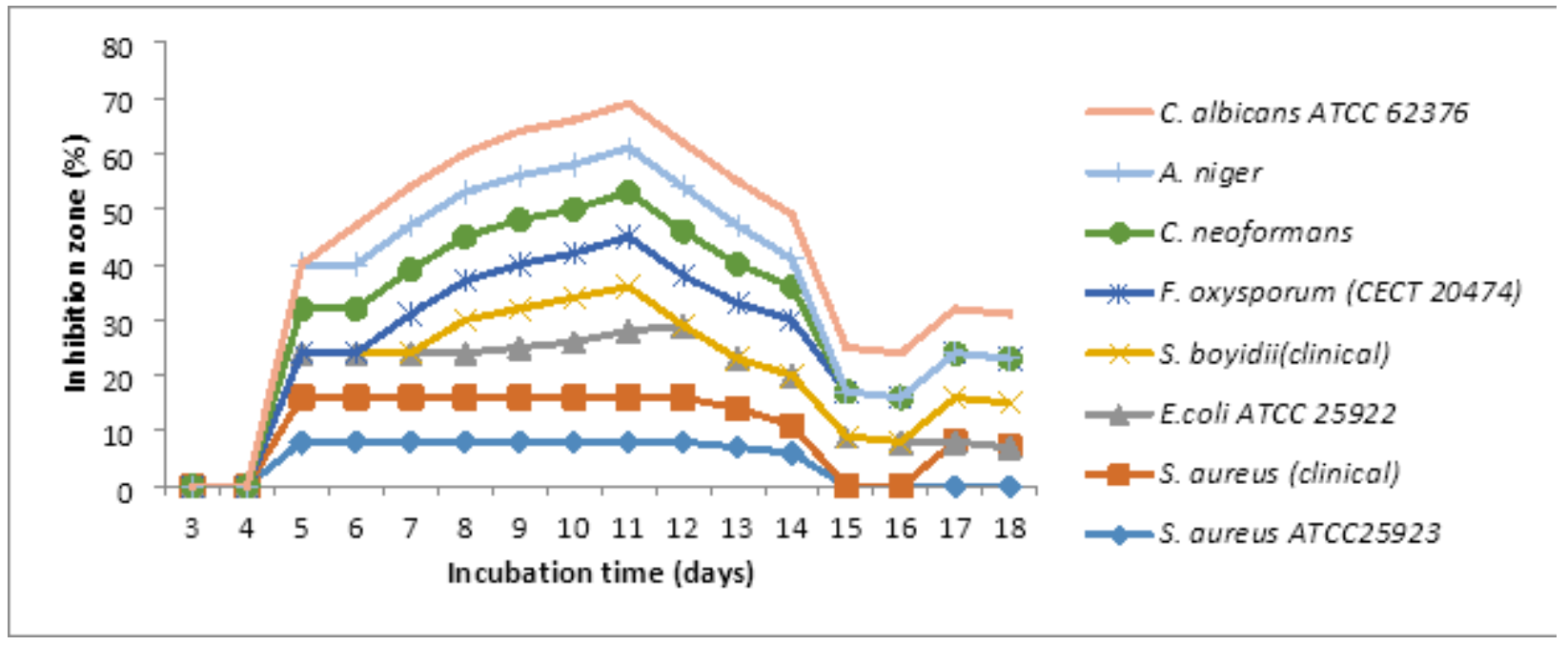

\section{Figure 1}

Zone of inhibition (measurement includes the diameter of the disc $6 \mathrm{~mm}$ ) of an antibacterial antifungal metabolite of LC-13-23 taken at different incubation periods (day).

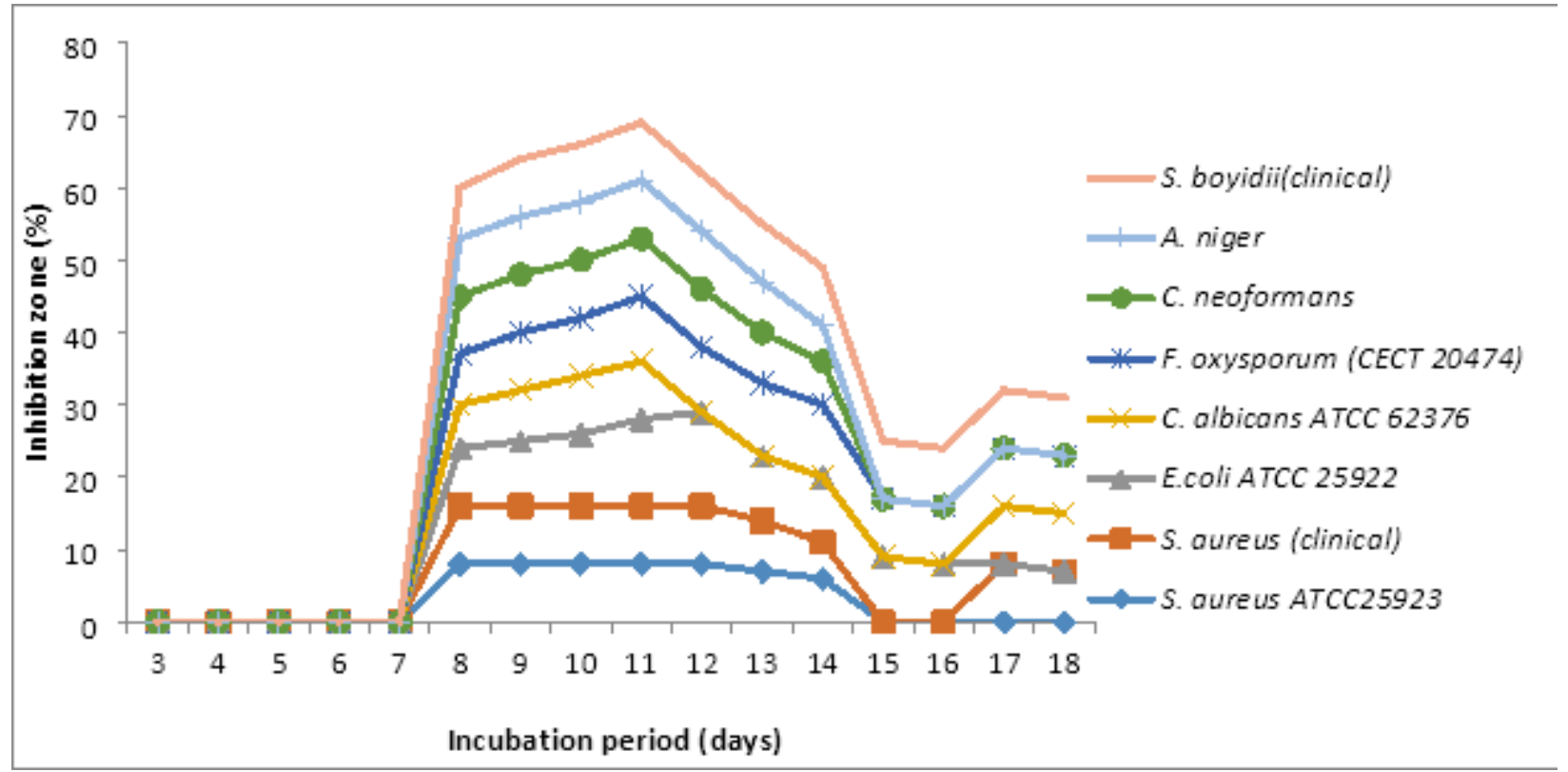

\section{Figure 2}

Diameter of zone of inhibition $(\mathrm{mm})$ of an antibacterial and antifungal metabolite of LAAACC15 taken at different incubation periods (day). 


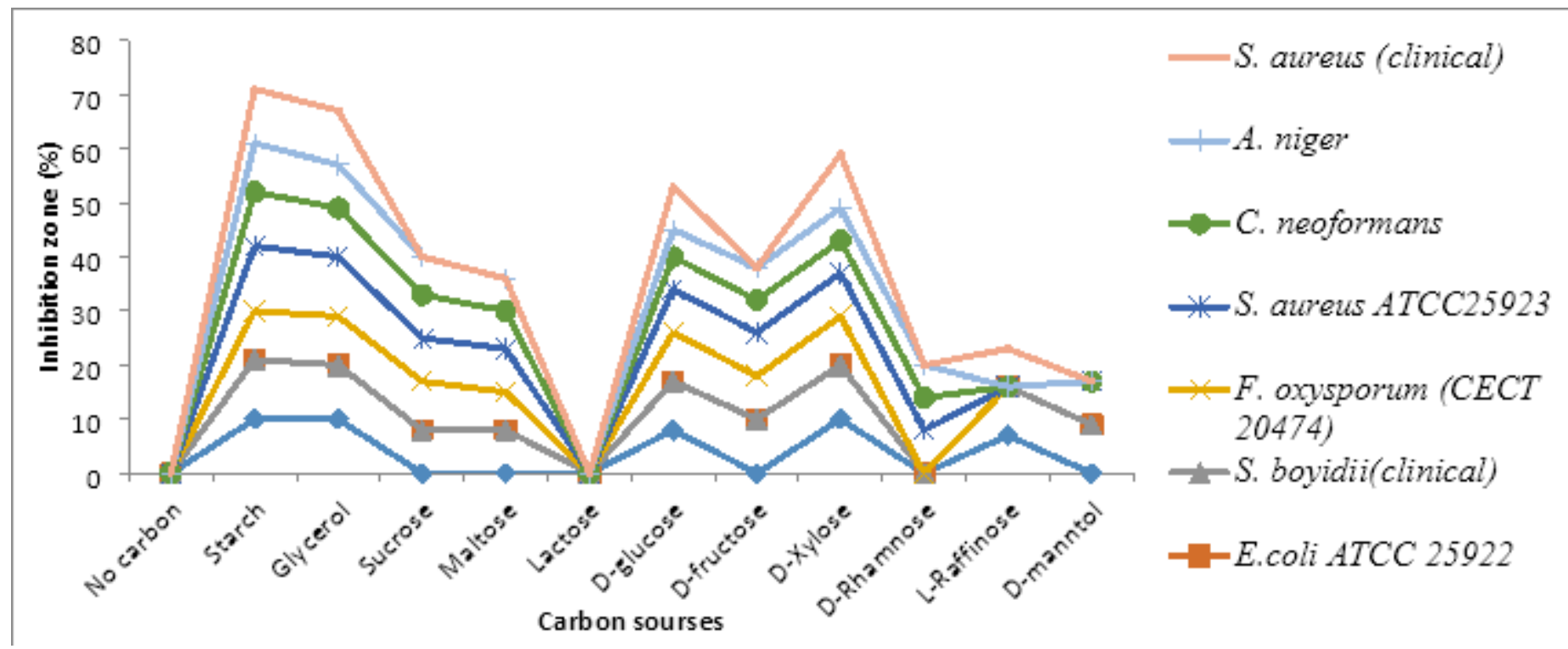

Figure 3

Diameter of the disc $(6 \mathrm{~mm})$ of zone of inhibition of LCHAACC13 grown on different carbon sources.

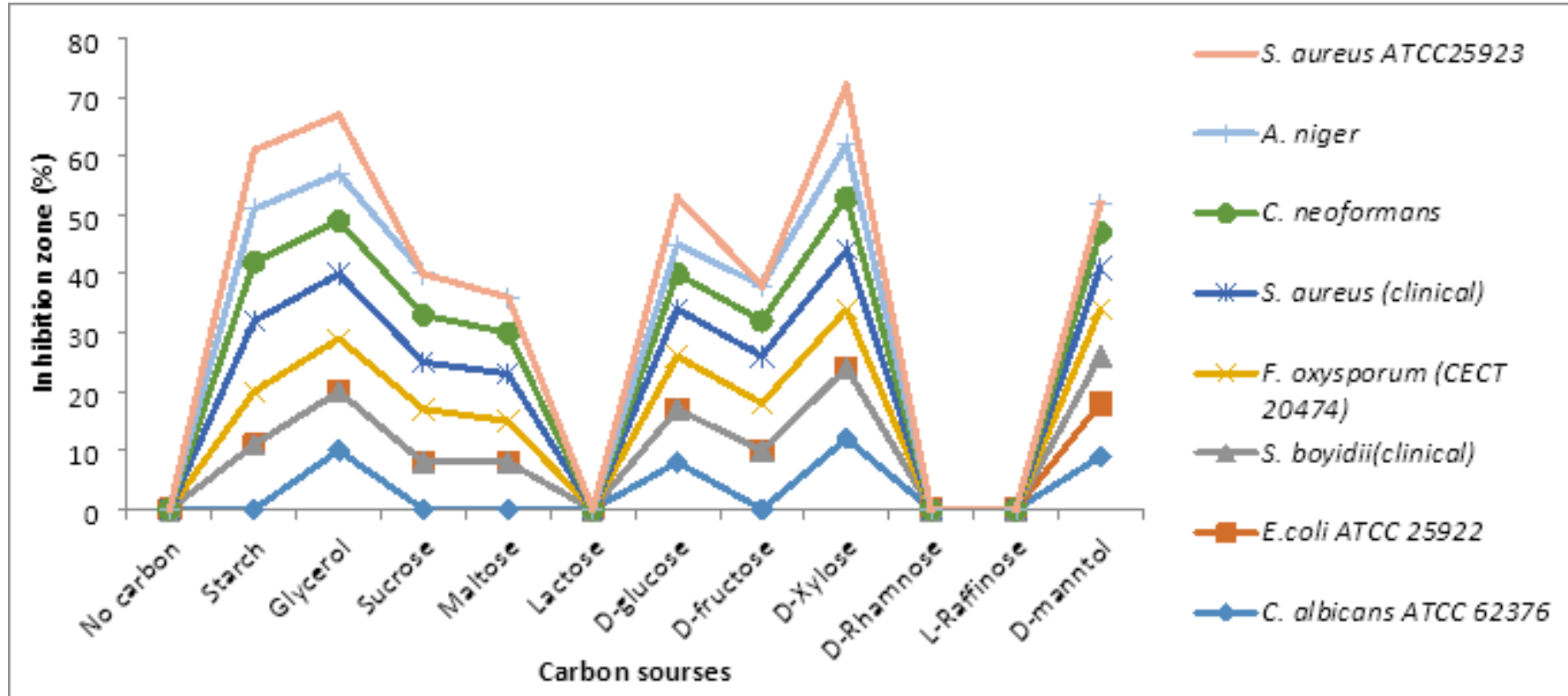

Figure 4

Diameter of zone of inhibition of LAAACC15 grown on different carbon sources. 


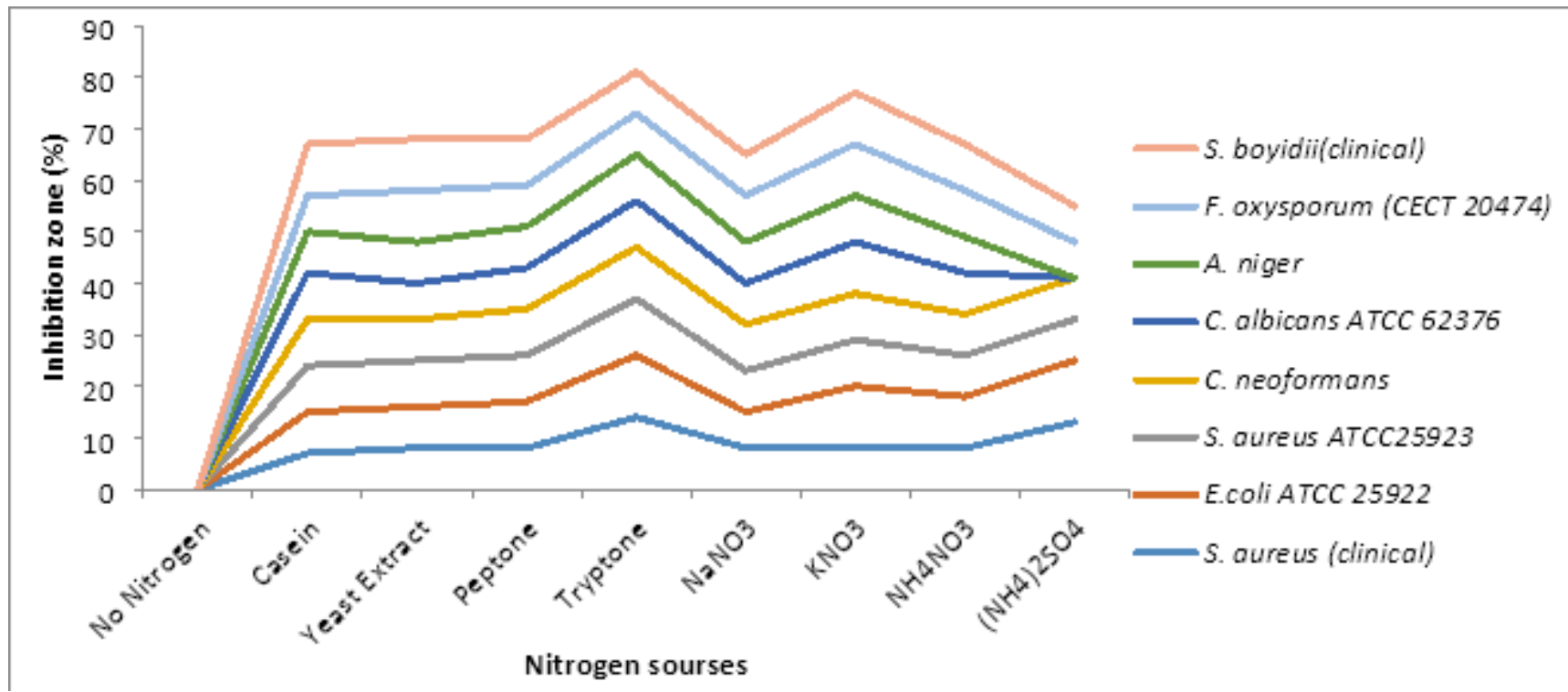

Figure 5

Diameter of zone of inhibition in mm of LCHAACC13 grown on different nitrogen sources.

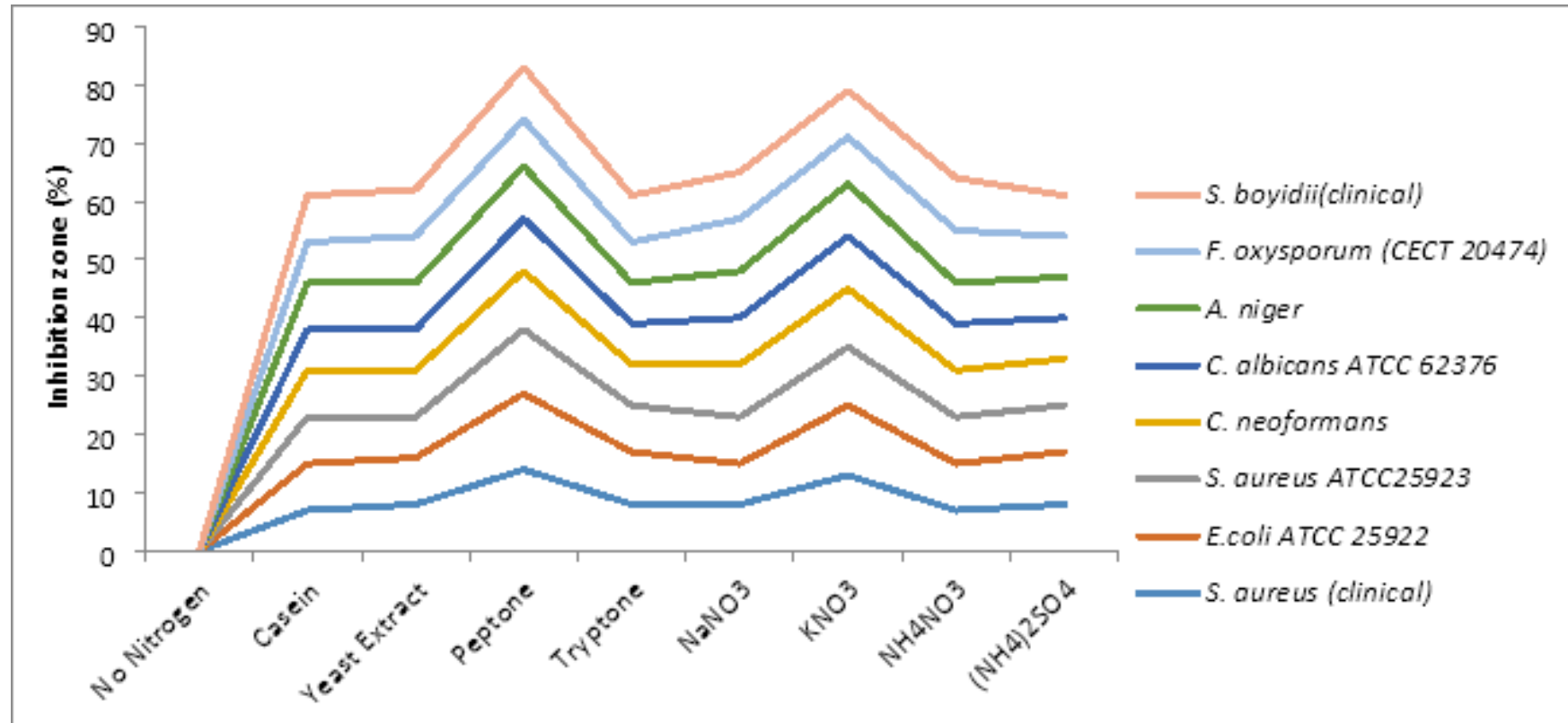

$\mathrm{N}$-sourses

\section{Figure 6}

Diameter of zone of inhibition zone in mm of LAAACC15 grown on different nitrogen sources against 


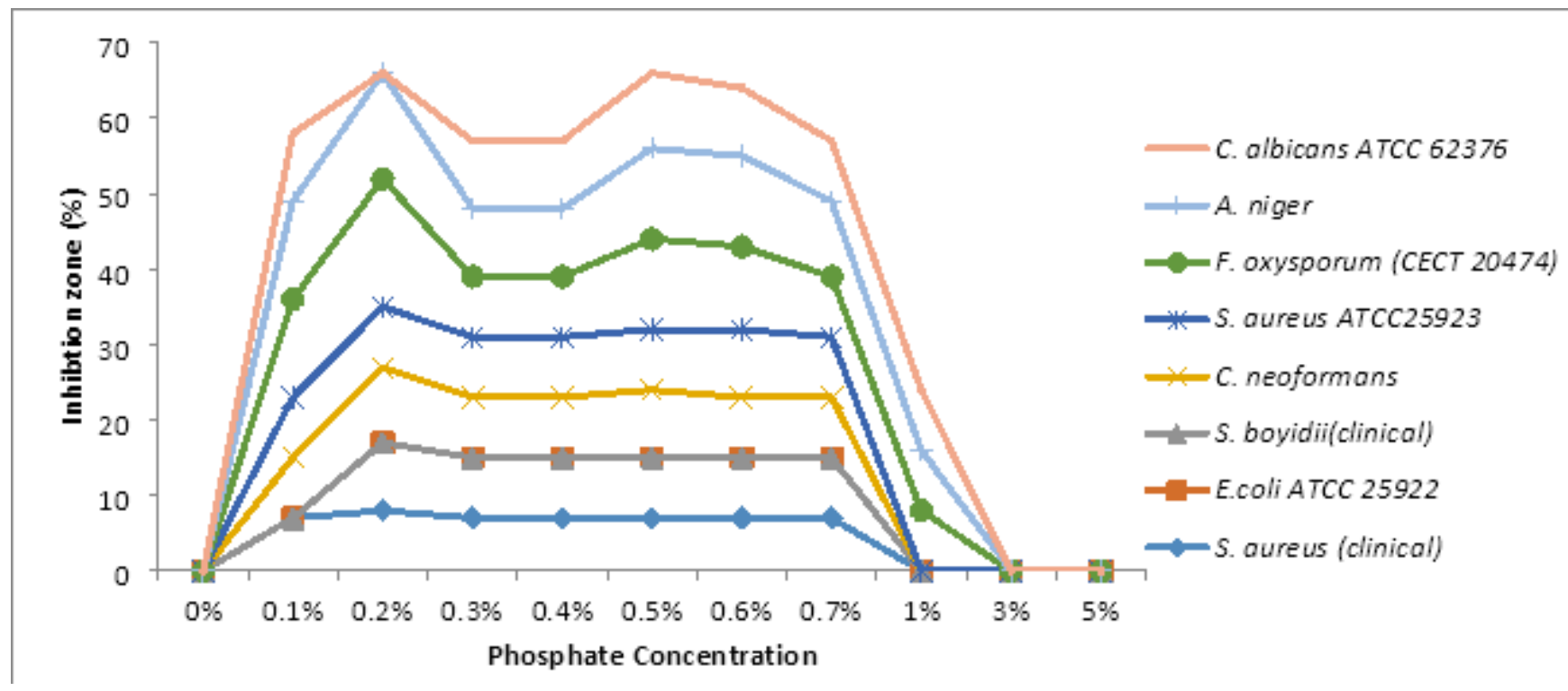

Figure 7

Extracted crude filtrate of LCHAACC13on 12th day on different K2HPO4 concentrations and antibacterial activity.

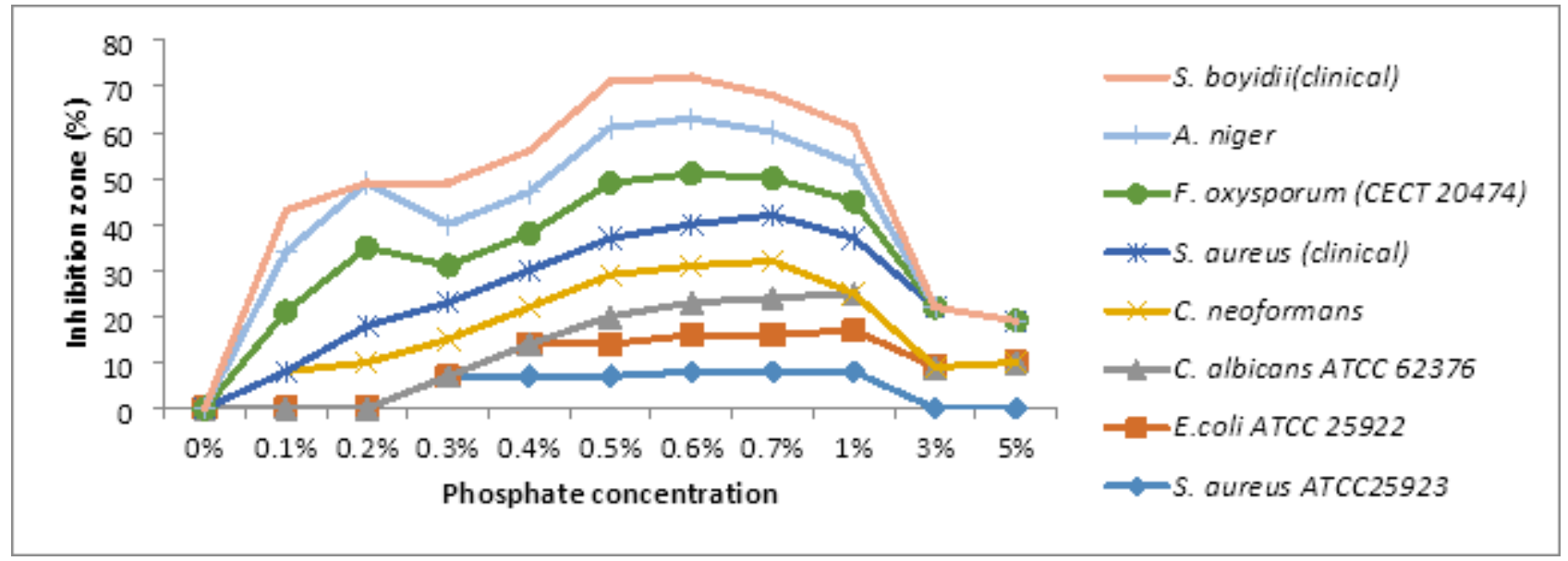

Figure 8

Extracted crude filtrate of LAACC15 on 14th day on different phosphate concentrations and diameter of zone of inhibition in $6 \mathrm{~mm}$ disc. 


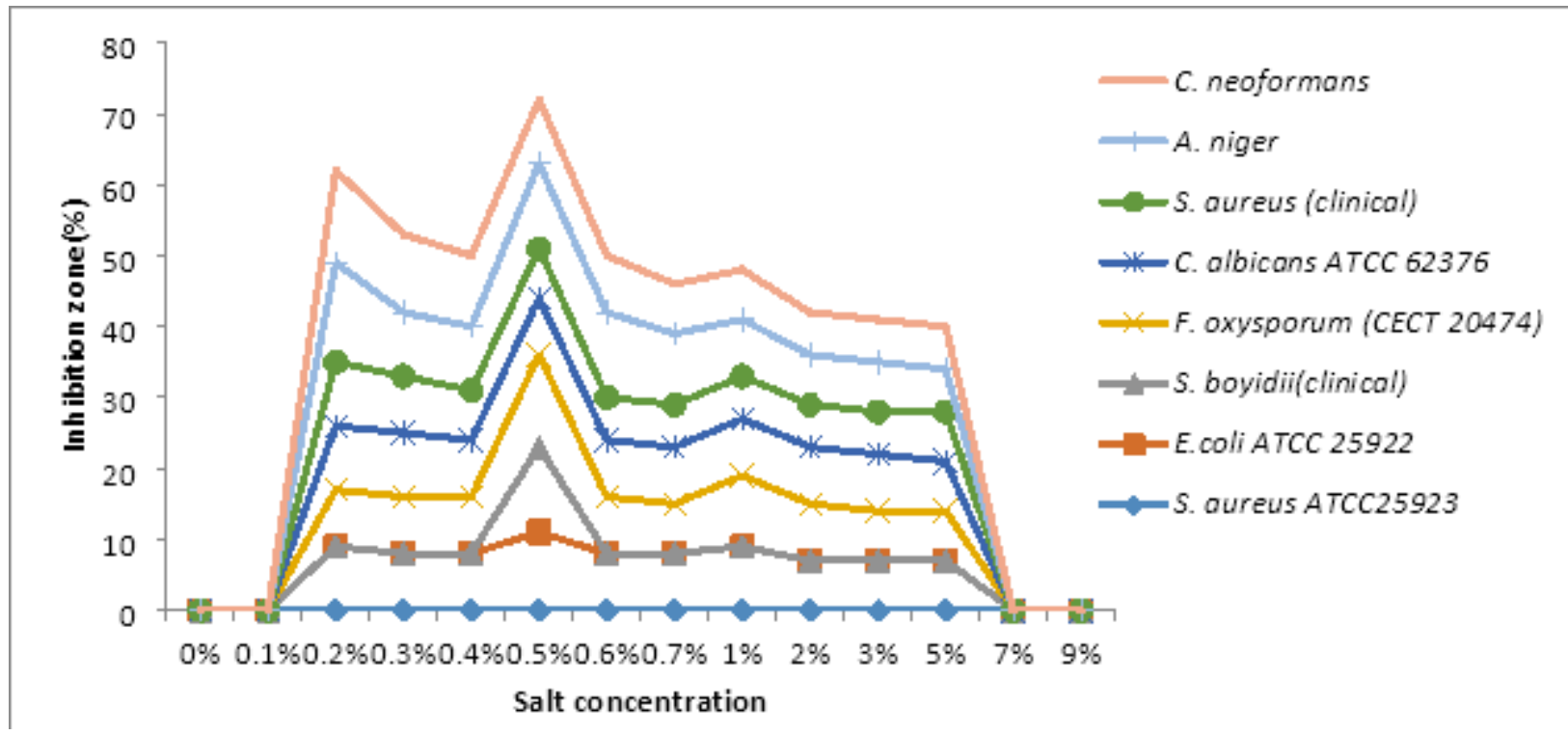

Figure 9

Test microorganisms and diameter of zone of inhibition in mm of LCHACC13 grown on different $\mathrm{NaCl}$ concentrations.

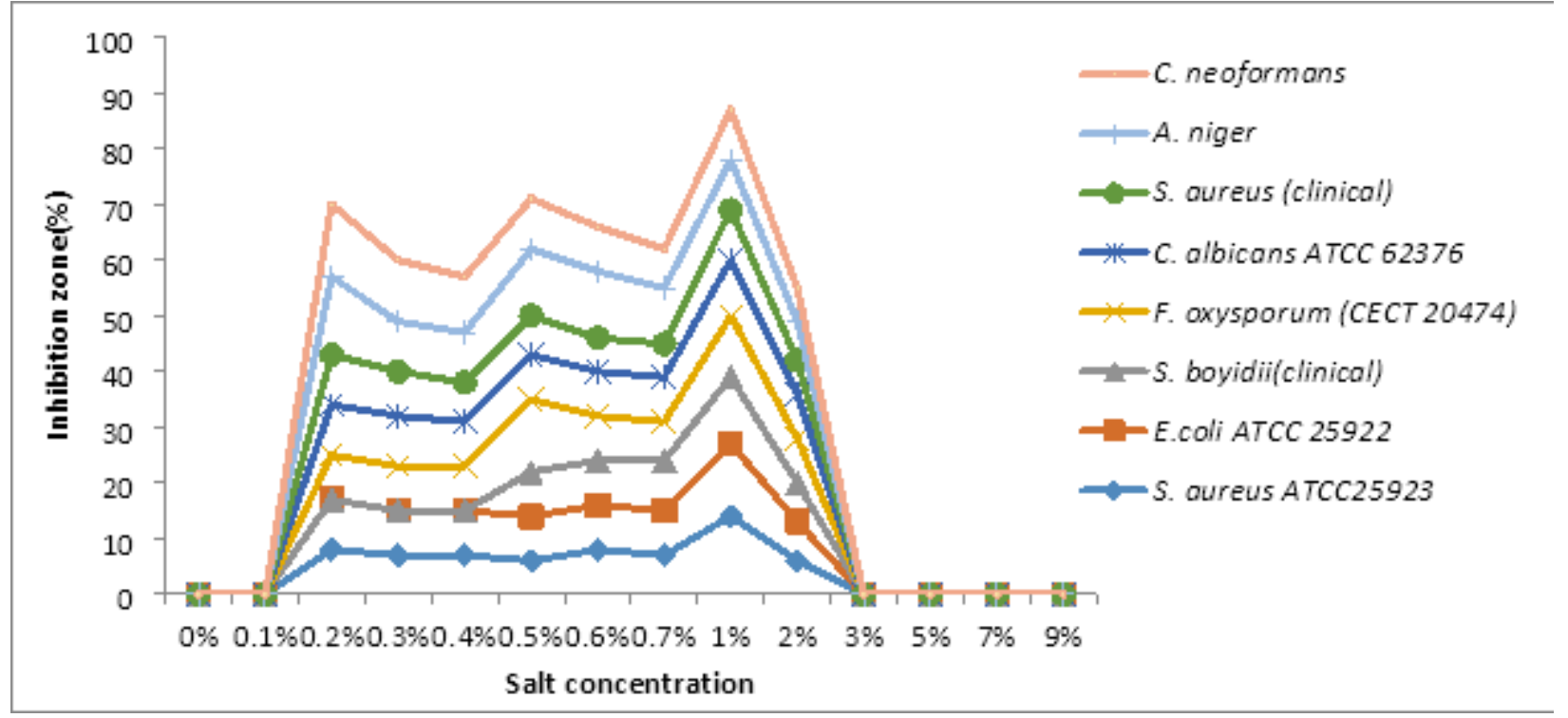

Figure 10

Test microorganisms and diameter of zone of inhibition in mm of LAACC15 grown on different $\mathrm{NaCl}$ concentrations. 


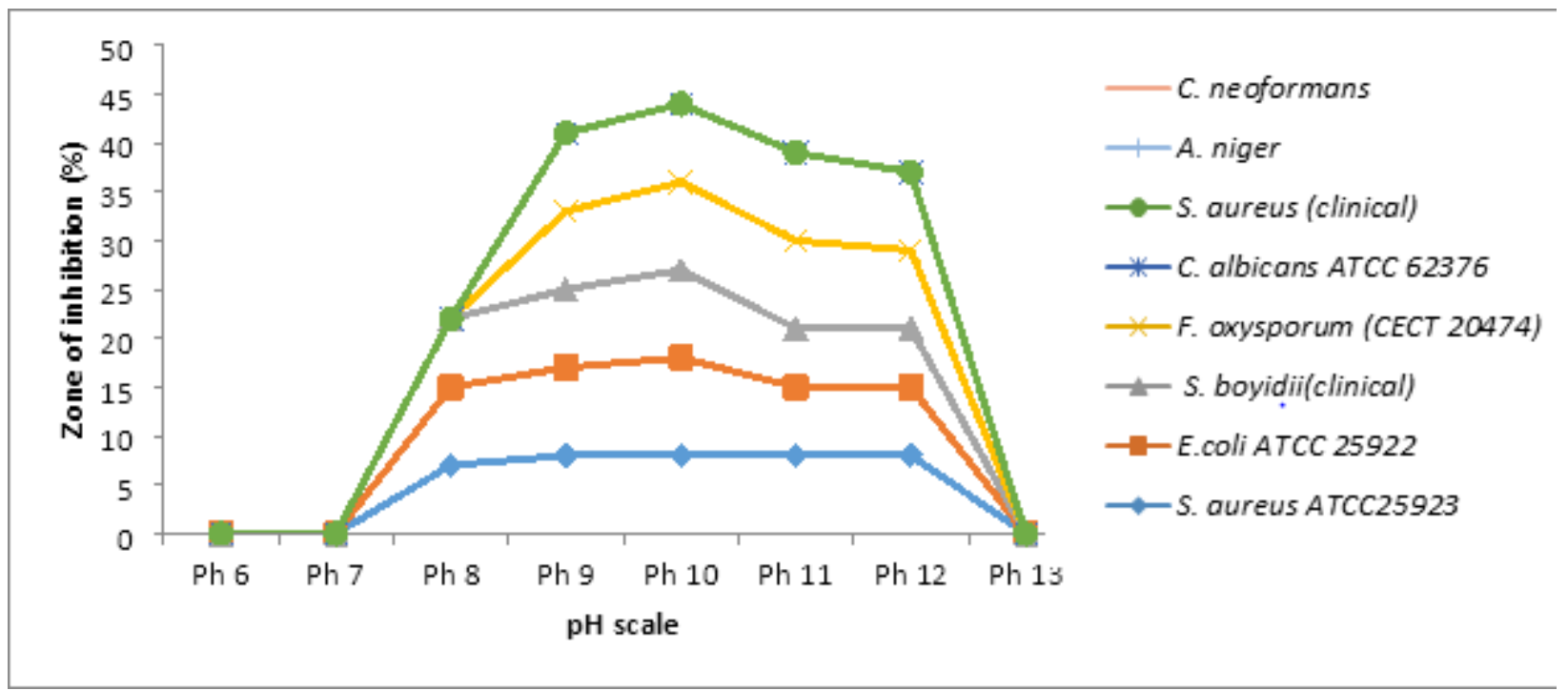

Figure 11

Diameter of zone of inhibition of LCHAACC 13 grown on different $\mathrm{pH}$

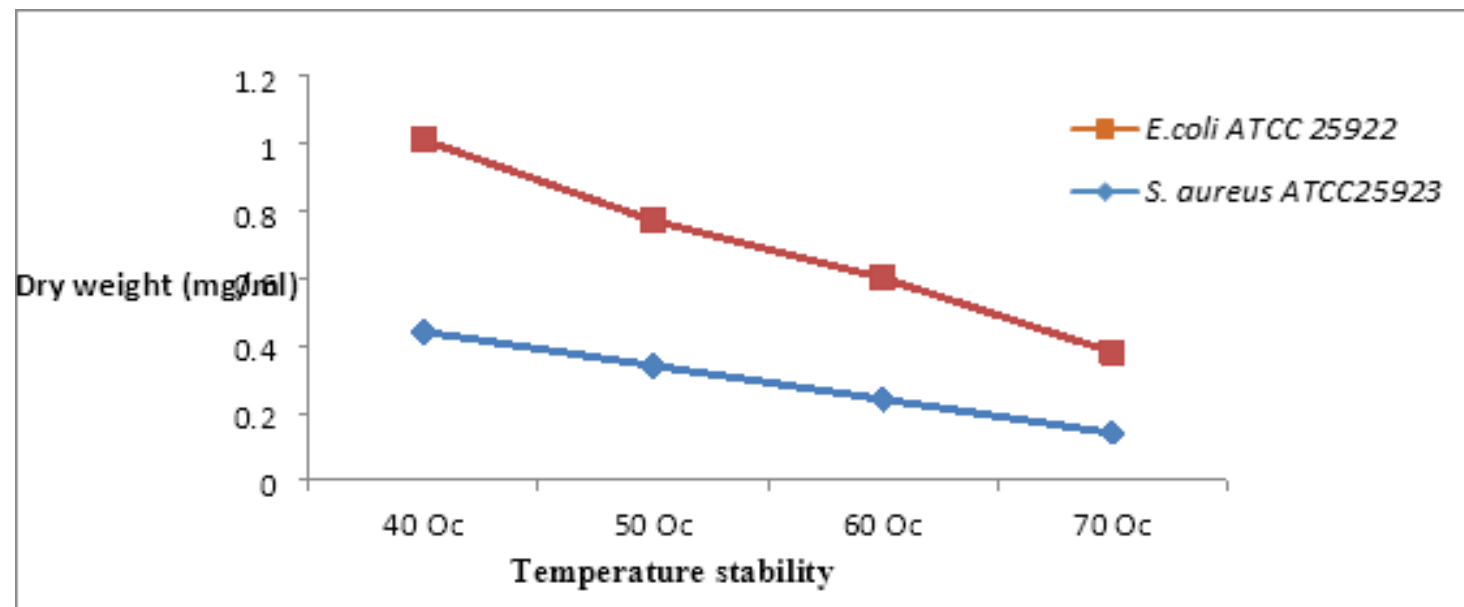

Figure 12

Temperature stability of isolates of two soda lakes. Both isolates of LCHAACC13 and LAAACC15 had the stability of $40 \mathrm{oC}-60 \mathrm{oC}$, but the range of a temperature supporting good growth was as wide as 20 oC30 oC. 


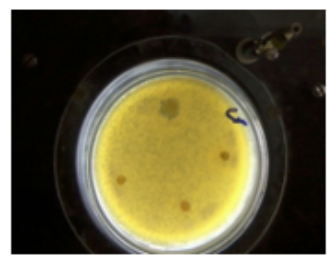

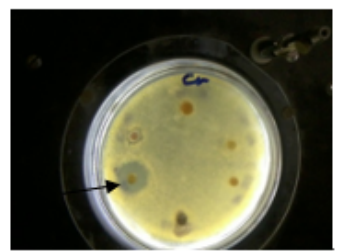

A.

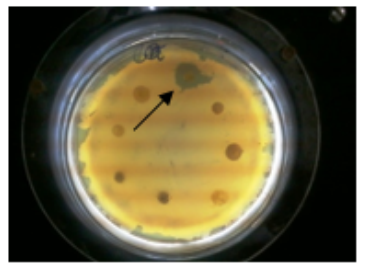

C.

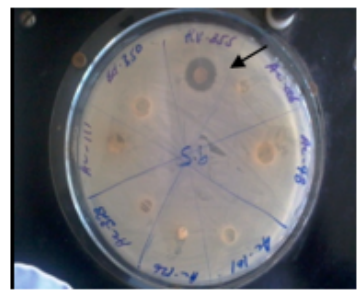

E.

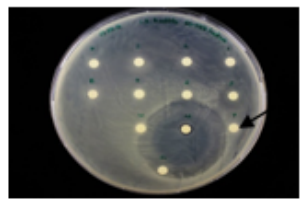

G.

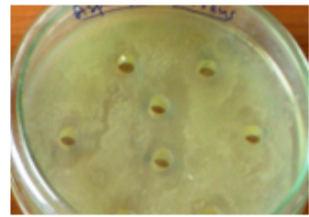

I.
B.

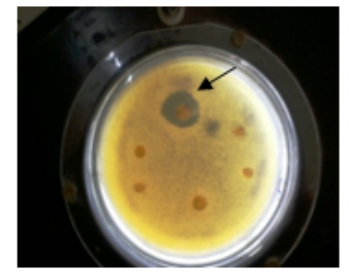

D.

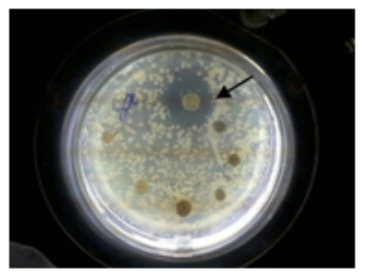

F.

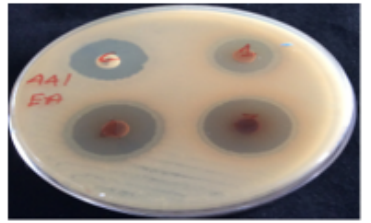

$\mathrm{H}$.

\section{Figure 13}

Inhibition of some representative test organisms by the extracts from selected Streptomyces spp. Inhibition of some test organisms by the extracts of 8 active isolates from selected Streptomyces species. A. Lc-13 against C. neoformans B. LC-15 against C. neoformans C. LC-17 against C. albicans D. La-13 against C. neoformans E. Lc-19 against S. boydii F. Lc-21 against S. aureus (clinical) G. La-15against S. 
aureus H. La-15 against F. oxysporum (CECT 20474). I. La-17 against Aspergillus niger. N.B: LC- stands for active isolates of Lake Chitu (LC); La- active isolates of Lake Arenguade (La)

\section{Supplementary Files}

This is a list of supplementary files associated with this preprint. Click to download.

- Preliminaryantimicrobialscreeningof10activeisolatesagainstdifferentmicrobialpathogens.docx

- Fungalprimaryculture.jpg

- Purecultureoffungalgeneraforprimaryscreening.jpg

- Monop2.jpg

- pink.jpg

- Incubationinincubator.jpg 